\title{
Numerical prediction of early age concrete temperature via 3D finite difference simulation
}

\author{
MP Dissanayaka and HD Yapa* \\ Department of Civil Engineering, Faculty of Engineering, University of Peradeniya, Peradeniya.
}

\begin{abstract}
Cement hydration is an exothermic reaction. It leads to increase in temperature and creates temperature gradients inside concrete structures during early ages. Extremes of such scenarios cause cracking of concrete and, therefore, affect the structural integrity and durability. Hence, prediction of temperature development of the concrete interior is vital in order to identify appropriate temperature control mitigation measures. However, it remains a challenge because, on the one hand, the governing thermal equations do not have closedform solutions, and on the other hand, the thermal behaviour of concrete is influenced by numerous factors, including heat evolution, heat conduction/convection, boundary conditions, etc. One possible solution is to implement numerical modelling via finite element (FE) or finite difference (FD) approaches. Amongst the two approaches, the former has a better simulating capacity to deal with complex problems, whereas the latter is relatively simple and less expensive. In this light, this research expanded an existing 2-dimentional FD temperature prediction tool towards a 3-dimentional (3D) model in view of enhancing the prediction accuracy of the $2 \mathrm{D}$ version. The 3D model was validated for three distinct experiments, and the prediction accuracy was found to be notable where the maximum temperature prediction offset was below $2.2 \%$. Then, the significance of using 3D FD temperature modelling for cube shape concrete structures and for pipe-cooled concrete structures was highlighted.
\end{abstract}

Keywords: 3D modelling, concrete temperature, finite difference.

\section{INTRODUCTION}

The hydration of cement is an exothermic reaction. Consequently, internal temperature development is a major concern prevailing with mass concrete construction. High temperature is undesirable for concrete due to a number of reasons. On the one hand, temperature beyond $70{ }^{\circ} \mathrm{C}$ could be a cause of delayed ettringite formation (Taylor et al., 2001), and on the other, concrete has low thermal conductivity, and it dissipates heat to the environment at the boundaries. Consequently, the heat generation leads to internal temperature gradients which could cause undesirable cracking effects (Neville, 2011). For instance, the temperature gradient limit applicable for concrete with gravel aggregate is about $20{ }^{\circ} \mathrm{C}$ (Bamforth, 2007). Also, in externally restrained structures, the drop of temperature during the cooling phase introduces tensile stresses that lead to undesirable cracking (Bamforth, 2007). It is therefore vital to take appropriate measures to control temperature development in concrete. Several temperature controlling methods are practised by the construction industry. The traditional methods include the use of low-heat concrete, use of pre-cooling methods (e.g., use of chilled water), and application of appropriate curing. The use of watercooled pipes (Myers et al., 2009; Li et al., 2012) and air-

\footnotetext{
${ }^{*}$ Corresponding author (hdy@pdn.ac.lk; (iD https://orcid.org/0000-0002-7213-5276)
} 
cooled pipes (Azenha et al., 2014) are relatively modern options applicable for temperature control of concrete.

The temperature development of concrete depends on many factors, including heat evolution of concrete, time, thermal conductivity, convection at the boundaries, and boundary conditions (Ballim, 2004). The heat transfer inside the concrete involves a number of interrelated mechanisms where none of which has a closedform solution. Hence, accurate temperature prediction is complex, and consequently, the identification of the appropriate temperature controlling requirement is always a challenge (Ballim, 2004). In this context, numerical approaches of Finite Element (FE) and Finite Difference (FD) methods have been effectively used as a temperature prediction tool for concrete structures (Ballim, 2004; Bobko et al., 2015; Dissanayake et al., 2017). The FE method is a complex approach, but it can be used to model sophisticated problems, including irregular geometry, diverse boundary conditions, construction patterns, etc. However, commercially available FE software packages are usually expensive (Bobko et al., 2015). In contrast, the applicability of the FD method is limited to regular shape structures, whereas it is relatively a less complex formulation (Ballim, 2004). Hence, the FD method also occupies a unique demand amongst the concrete temperature modelling options. Numerous successful investigations that explored 2-dimensional (2D) FD concrete temperature modelling are found in the literature (Ballim, 2004; Bobko et al., 2015; Yikici \& Chen, 2015). However, an extension of the FD approach towards 3-dimensional (3D) modelling has seldom been investigated in spite of the 3D predictions that should necessarily be more precise than the $2 \mathrm{D}$ results, particularly for structures with heat flow across all three directions. Also, if the modelling of pipe-cooling systems is to be facilitated, necessarily the use of 3D simulation is vital. In this context, as an expansion of the commonly used 2-dimensional (2D) FD concrete temperature modelling, this research explored the use of 3-dimensional (3D) FD modelling to predict the temperature in concrete structures.

\section{METHODOLOGY}

A literature survey was conducted to explore the application of the FD approach to predict the temperature development in concrete. Based on the existing 2D models, the formulation was extended to a 3D FD formulation. The 3D model was then validated on available experimental results and subsequently was utilised on parametric studies to identify the contexts where 3D simulation is significant. Also, the potential of the 3D model to simulate pipe-cooled concrete systems was assessed. These steps of the methodology are further elaborated in the following sections.

\section{Temperature prediction model development}

\section{Heat flow relations}

Conduction of heat across a mass can be expressed in the Fourier equation form by,

$$
q=-k A \frac{\partial T}{\partial x}
$$

where $q$ is the heat transfer rate, $k$ is the thermal conductivity, $A$ is the cross-sectional area, and $\frac{\partial T}{\partial x}$ is the temperature gradient in the direction of the heat flow (Holman, 1986). The minus sign indicates that the heat flow is in the direction of temperature reduction.

Considering the energy balance in a body where a heat source exists, the expression for one-dimensional heat flow can be obtained in the form of,

$\frac{\partial}{\partial x}\left(k \frac{\partial T}{\partial x}\right)+Q^{\prime}=\rho c \frac{\partial T}{\partial t}$

where $Q^{I}$ is the rate of heat generated per unit volume, $p$ is the density of the material, $c$ is the specific heat capacity of the material, and $\frac{\partial T}{\partial t}$ is the rate of change of temperature (Holman, 1986). It is, therefore, possible to extend equation 2 to obtain the 3D heat flow as,

$k\left(\frac{\partial^{2} T}{\partial x^{2}}+\frac{\partial^{2} T}{\partial y^{2}}+\frac{\partial^{2} T}{\partial z^{2}}\right)+Q^{\prime}=\rho c \frac{\partial T}{\partial t}$

where $x, y, z$ are the coordinates at a particular point in the structure. It is assumed here that the thermal conductivity in each direction is similar.

\section{Development of finite difference (FD) equations}

The FD method gives a point-wise solution to the governing differential equations by using a finite set of points (Patini, 2011). Ballim (2004) developed an FD model, which is a 2D solution for the Fourier equation for heat flow in solid bodies. By extending his work via equation 3, this study developed $\mathrm{FD}$ equations for seven distinct nodal positions, as shown in Figure 1 (a) for a cubical (3D) concrete block. These equations are expressed in equations 4 to 12 . 


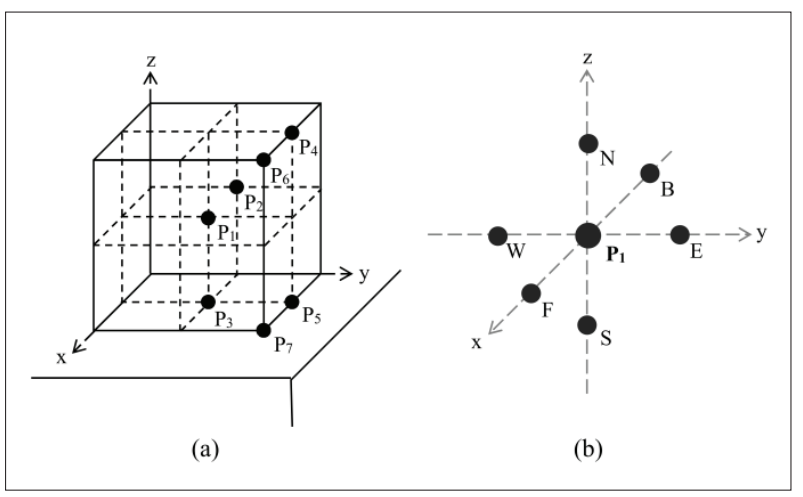

Figure 1: (a) Nodal locations and (b) nodal arrangement for an internal node

For an internal node P1 [shown in Figures 1 (a) and (b)], the 3D FD equation can be formulated to be:

$$
\begin{aligned}
T_{P_{1}}^{n+1}= & \frac{Q^{n} \delta t}{\rho c}+T_{P_{1}}^{n}\left(1-6 F_{0}\right) \\
& +F_{0}\left(T_{N}^{n}+T_{E}^{n}+T_{S}^{n}+T_{W}^{n}+T_{F}^{n}+T_{B}^{n}\right)
\end{aligned}
$$

subjected to $\delta t \leq \frac{\rho c \Delta^{2}}{6 k}$

Here $T_{P_{1}}^{n+1}$ is the temperature at node $\mathrm{P}_{1}$ in the $(n+1)^{\text {th }}$ time interval (similar notation is applicable to all the other nodal positions), $Q^{\prime}$ is the rate of internal heat evolution in the $n^{\text {th }}$ time interval, $\delta t$ is the time-step interval used in the FD analysis and $F_{0}$ is the Fourier number, which is defined as,

$$
F_{0}=\frac{k \delta t}{\rho c \Delta^{2}}
$$

where $\Delta=\Delta_{x}=\Delta_{y}=\Delta_{z}$ is the nodal distance. Also, $T_{N}, T_{E}, T_{S}, T_{W}, T_{F}, T_{B}$ are the temperatures of the nodes to the north, east, south, west, front, and back of node $\mathrm{P}_{1}$ during this particular time interval [see Figure 1 (b)].

Similarly, the FD equation for an exposed surface node $\mathrm{P}_{2}$ is,

$$
\begin{aligned}
T_{P_{2}}^{n+1}= & \frac{Q^{n} \delta t}{\rho c}+T_{P_{2}}^{n}\left(1-F_{0}\left(6+2 B_{i}\right)\right) \\
& +F_{0}\left(T_{N}^{n}+T_{E}^{n}+T_{S}^{n}+T_{W}^{n}+2 T_{F}^{n}+2 B_{i} T_{A}^{n}\right)
\end{aligned}
$$

subjected to $\delta t \leq \frac{\rho c \Delta^{2}}{(6 k+2 h \Delta)}$

where $T_{A}$ is the ambient temperature and $B_{i}$ is the Biot number, which is defined as,

$B_{i}=\frac{h \Delta}{k}$

where $h$ is the heat transfer coefficient.

The bottom surface node FD equation is,

$$
\begin{aligned}
T_{P_{3}}^{n+1} & =\frac{Q^{\prime n} \delta t}{\rho c}+T_{P_{3}}^{n}\left(1-F_{0}\left(6+2 \frac{k_{R}}{k}\right)\right) \\
& +F_{0}\left(T_{E}^{n}+T_{W}^{n}+T_{F}^{n}+T_{B}^{n}+2 T_{N}^{n}+2 \frac{k_{R}}{k} T_{R}^{n}\right)
\end{aligned}
$$

subjected to $\delta t \leq \frac{\rho c \Delta^{2}}{\left(6 k+2 k_{R}\right)}$

where $k_{R}$ is the thermal conductivity of the base material (rock) and $T_{R}$ is the base temperature.

The FD equation for an exposed edge node $\mathrm{P}_{4}$ is,

$$
\begin{aligned}
T_{P_{4}}^{n+1}= & \frac{Q_{n}^{\prime} \delta t}{\rho c}+T_{P_{4}}^{n}\left(1-F_{0}\left(6+4 B_{i}\right)\right) \\
& +F_{0}\left(T_{F}^{n}+T_{B}^{n}+2 T_{S}^{n}+2 T_{W}^{n}+4 B_{i} T_{A}^{n}\right)
\end{aligned}
$$

subjected to $\delta t \leq \frac{\rho c \Delta^{2}}{(6 k+4 h \Delta)}$

The FD equation for a bottom edge node $\mathrm{P}_{5}$ is,

$$
\begin{aligned}
T_{P_{5}}^{n+1}= & \frac{Q_{n}^{\prime} \delta t}{\rho c}+T_{P_{5}}^{n}\left(1-F_{0}\left(6+2 B_{i}+2 \frac{k_{R}}{k}\right)\right) \\
& +F_{0}\left(T_{F}^{n}+T_{B}^{n}+2 T_{N}^{n}+2 T_{W}^{n}\right. \\
& \left.+2 B_{i} T_{A}^{n}+2 \frac{k_{R}}{k} T_{R}^{n}\right)
\end{aligned}
$$

subjected to $\delta t \leq \frac{\rho c \Delta^{2}}{\left(6 k+2 h \Delta+2 k_{R}\right)}$

The top corner node $\mathrm{P}_{6} \mathrm{FD}$ equation is,

$$
\begin{aligned}
& T_{P_{6}}^{n+1}=\frac{Q_{n}^{\prime} \delta t}{\rho c}+T_{P_{6}}^{n}\left(1-6 F_{0}\left(1+B_{i}\right)\right) \\
& +2 F_{0}\left(T_{S}^{n}+T_{W}^{n}+T_{B}^{n}+3 B_{i} T_{A}^{n}\right)
\end{aligned}
$$


subjected to $\delta t \leq \frac{\rho c \Delta^{2}}{6(k+h \Delta)}$ and, that for a bottom corner node $\mathrm{P}_{7}$ is,

$$
\begin{aligned}
T_{P_{7}}^{n+1}= & \frac{Q_{n}^{\prime} \delta t}{\rho c}+T_{P_{7}}^{n}\left(1-F_{0}\left(6+4 B_{i}+2 \frac{k_{R}}{k}\right)\right) \\
& +2 F_{0}\left(T_{N}^{n}+T_{W}^{n}+T_{B}^{n}+\frac{k_{R}}{k} T_{R}^{n}+2 B_{i} T_{A}^{n}\right)
\end{aligned}
$$

subjected to $\delta t \leq \frac{\rho c \Delta^{2}}{\left(6 k+4 h \Delta+2 k_{R}\right)}$

\section{Determination of internal heat evolution}

Several options are available to estimate the internal heat evolution of concrete. The use of analytical models is one such possibility (Bamfoth, 2007), where the concrete composition is usually the main parameter in such models. Matharaarachchi et al. (2012) showed the potential of using a more detailed analytical model that was based on the composition of the cement constituents for obtaining highly accurate temperature predictions for concrete structures. Nevertheless, the use of calorimeter test results is deemed to be a more accurate option to quantify the internal heat evolution of concrete (Riding et al., 2006), hence it was opted in the current study. This test can be conducted either in the adiabatic or semi-adiabatic condition - in the latter case, heat loss compensation is to be carried out in order to obtain the adiabatic behaviour. Details of calorimeter tests and heat loss compensation methods can be found elsewhere (Ng et al., 2008; Wasala \& Yapa, 2017).

In the Fourier equation, the term $Q^{\prime}$ is used to account for the rate of heat evolution, and it is determined by differentiating the total heat with respect to time, which is called the time-based heat rate (Ballim, 2004). This can be expressed by,

$Q^{\prime}=\frac{d Q}{d T}$

where,

$Q=m c \delta T$

and $m$ is the mass of the sample, $c$ is the concrete specific heat, and $\delta T$ is the change in temperature of the sample over the time period. The extent and the rate of cement hydration depend on the absolute temperature under which the reaction takes place. The temperature of hardening concrete varies from point to point, and therefore, each point has a unique time-temperature profile (Ballim, 2004). To address this phenomenon, the time component in the heat relations is to be incorporated with maturity where the maturity based heat rate is given by,

$Q_{M}^{\prime}=\frac{d Q}{d M}$

where, $M$ is the maturity time. Accordingly, the time-based heat rate becomes to the form of,

$Q^{\prime}=Q_{M}^{\prime} \frac{d M}{d t}$

Amongst commonly used maturity functions, the Arrhenius function provides a good basis to determine maturity-based heat rate (Ballim \& Graham, 2003). It details the maturity of concrete cured at any temperature to be an equivalent maturity time $\left(t_{20}\right)$ of concrete cured at $20^{\circ} \mathrm{C}$, and is expressed as,

$t_{20}=\sum_{i=1}^{n} \exp \left[\left(\frac{E}{R}\right)\left(\frac{1}{293}-\frac{1}{273+0.5\left(T_{i}-T_{i-1}\right)}\right)\right]\left(t_{i}-t_{i-1}\right)$

where $E$ is the activation energy parameter, $R$ is the universal gas constant $\left(8.31 \mathrm{~J} / \mathrm{mol}{ }^{\circ} \mathrm{C}\right)$, and $T_{i}$ is the temperature (in ${ }^{\circ} \mathrm{C}$ ) at the end of the $\mathrm{i}^{\text {th }}$ time interval $t_{i}$. It is of note that $E$ is governed by the material, and Soutsos et al. (2017) report that it could be in the range of $30-50 \mathrm{~kJ} / \mathrm{mol}$ for OPC based concrete.

\section{Temperature prediction algorithm development}

The MATLAB software was used for programming the FD model. Using the FD solutions of the Fourier equation for $3 \mathrm{D}$ heat flow for distinct nodal locations, an algorithm was formulated to model structural and boundary configurations for a given concrete structure.

The inputs for the algorithm were nodal distance $(\Delta)$, time interval $t$, number of cycles to be run $(n)$, density $(\rho)$, specific heat capacity $(c)$, and thermal conductivity $(k)$ of concrete, thermal conductivity $\left(k_{R}\right)$ and temperature $\left(T_{R}\right)$ of the base material, heat transfer coefficients (convection) before and after formwork striking ( $h_{\text {plywood }}$ and $h_{\text {air }}$ ), formwork striking time $\left(t_{s}\right)$, ambient temperature variation $\left(T_{a}\right)$, concrete placing temperature $\left(T_{0}\right)$, and adiabatic temperature profile for the concrete mix. As the major output, the temperature profile with respect to time at any nodal location within the concrete block could be obtained. Based on the findings of Ballim (2004) on optimum levels of the nodal distance $(\Delta)$ and time interval $(\delta T)$, these two input parameters were maintained at $100 \mathrm{~mm}$ and $30 \mathrm{~min}$, respectively. It is 
noted that a FE approach might use a similar size for the concrete mesh whilst the time step could be considerably lower than that (Tahershima \& Tikalshy, 2017).

\section{FD Model validation}

\section{Experimental data selection}

The 3D prediction model was applied to three distinct experiments reported in the literature (Nanayakkara \& Wannigama, 2003; Ballim, 2004; Madupushpa et al., 2017) in order to verify the potential of the model for different block sizes, concrete mixes, environmental conditions, and boundary conditions. For instance, these experiments cover: concrete dimensions of $350 \mathrm{~mm}$ to
$1200 \mathrm{~mm}$, cement content of $220 \mathrm{~kg} / \mathrm{m}^{3}$ to $493 \mathrm{~kg} / \mathrm{m}^{3}$, ambient temperatures of $16-30{ }^{\circ} \mathrm{C}$. Table 1 shows the width $(w)$, height $(h)$, length $(l)$ of each experimental block and the cement content. Table 2 and Table 3 tabulate the thermal properties and the other parameters used in the analysis. These parameters were identified based on the information available from each literature source. In case of the absence of direct information, the thermal parameters were estimated with the guidelines in Bamforth (2007).

In the Ballim (2004) experiment, the temperature was monitored in a $700 \times 1000 \times 700 \mathrm{~mm}$ cuboid. The two opposite $700 \times 1000 \mathrm{~mm}$ surfaces were insulated using $20 \mathrm{~mm}$ thick styrofoam panels in addition to the $18 \mathrm{~mm}$

Table 1: Experimental data

\begin{tabular}{lcccc}
\hline Experiment & $w(\mathrm{~mm})$ & $h(\mathrm{~mm})$ & $l(\mathrm{~mm})$ & $\begin{array}{c}\text { Cement content } \\
\left(\mathrm{kg} / \mathrm{m}^{3}\right)\end{array}$ \\
\hline Ballim (2004) & 700 & 700 & 1000 & 220 \\
Nanayakkara \& Wannigama (2003) & 1000 & 1200 & 1200 & 400 \\
Madupushpa et al. (2017) & 350 & 700 & 1000 & 493 \\
\hline
\end{tabular}

Table 2: Concrete parameters used for the model verification

\begin{tabular}{lcccc}
\hline Experiment & $\begin{array}{c}\rho \\
\left(\mathrm{kg} / \mathrm{m}^{3}\right)\end{array}$ & $\begin{array}{c}c \\
\left(\mathrm{~J} / \mathrm{g}^{\circ} \mathrm{C}\right)\end{array}$ & $\begin{array}{c}k \\
\left(\mathrm{~W} / \mathrm{m}^{\circ} \mathrm{C}\right)\end{array}$ & $\begin{array}{c}T_{0} \\
\left({ }^{\circ} \mathrm{C}\right)\end{array}$ \\
\hline Ballim (2004) & 2400 & 1.23 & 3.5 & 17 \\
Nanayakkara \& Wannigama (2003) & 2366 & 1.38 & 2.7 & 32 \\
Madupushpa et al. (2017) & 2349 & 1.13 & 2.5 & 27.5 \\
\hline
\end{tabular}

Table 3: Other parameters used for the model verification

\begin{tabular}{lccccr}
\hline Experiment & $\begin{array}{c}k_{R} \\
\left(\mathrm{~W} / \mathrm{m}^{\circ} \mathrm{C}\right)\end{array}$ & $\begin{array}{c}T_{R} \\
\left({ }^{\circ} \mathrm{C}\right)\end{array}$ & $\begin{array}{c}\mathrm{h}_{\text {plywood }} \\
\left(\mathrm{W} / \mathrm{m}^{2}{ }^{\circ} \mathrm{C}\right)\end{array}$ & $\begin{array}{c}h_{\text {air }} \\
\left(\mathrm{W} / \mathrm{m}^{2}{ }^{\circ} \mathrm{C}\right)\end{array}$ & $\begin{array}{c}T_{a} \\
\left({ }^{\circ} \mathrm{C}\right)\end{array}$ \\
\hline Ballim (2004) & 1.2 & 18 & $2^{*}$ or 5 & 30 & $16-21$ \\
Nanayakkara \& Wannigama (2003) & 1.2 & 30 & $2^{*}$ or 8 & 14 & 30 \\
Madupushpa et al. (2017) & 1.2 & 29 & 6.5 & 23 & 29 \\
\hline
\end{tabular}

*Heat transfer coefficient for sides insulated from polystyrene

thick form board (in order to facilitate 2D heat flow). In the Nanayakkara and Wannigama (2003) experiment, a cuboid of $1000 \times 1200 \times 1200 \mathrm{~mm}$ was insulated with $12 \mathrm{~mm}$ thick plywood formwork and additionally, the two $1000 \times 1200 \mathrm{~mm}$ ends were insulated using $25 \mathrm{~mm}$ polystyrene panels. A concrete block with similar dimensions to the Ballim (2004) experiment was used in the Madupushpa et al. (2017) experiment, and $12 \mathrm{~mm}$ plywood formwork was used for all four vertical surfaces. In their experiment, there was a second block cast on top of the first block after 18 hours from the initial concrete placing (however this second cast was not considered in the current FD modelling).

Figure 2 shows the adiabatic temperature profiles (starting from the initial temperature) used for the analysis of the three experiments. It is of note that, for the FD modelling of the experiment in Nanayakkara and Wannigama (2003), the exact adiabatic detail was not available; hence an adiabatic temperature profile suitable 
for the concrete mix was chosen from the data in Wasala and Yapa (2017).

\section{Parametric study}

In order to identify the attributes of the $3 \mathrm{D}$ prediction model, a parametric study was conducted to compare

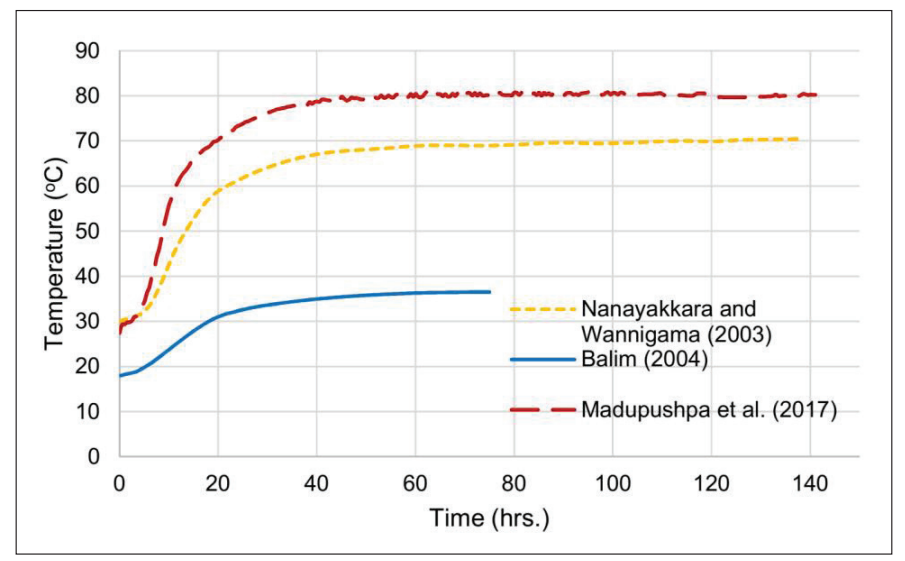

Figure 2: Adiabatic temperature profiles

2D and 3D FD temperature predictions for two distinct applications shown in Figure 3. Here, $1 \mathrm{~m}$ high $(z=1 \mathrm{~m})$ and $1 \mathrm{~m}$ wide $(y=1 \mathrm{~m})$ concrete block was considered where the length $(l)$ to width $(w)$ ratio $(l / w)$ was varied at 1 and 2. This selection was made presuming 3D modelling to be more accurate for the $l / w=1$ scenario, in which the heat flow in the $3^{\text {rd }}$ direction (along the length, $x$ direction) could be considerable.

\section{Temperature simulation of pipe-cooled concrete}

Another exclusive potential of 3D numerical modelling is the temperature simulation possibility of pipe-cooled

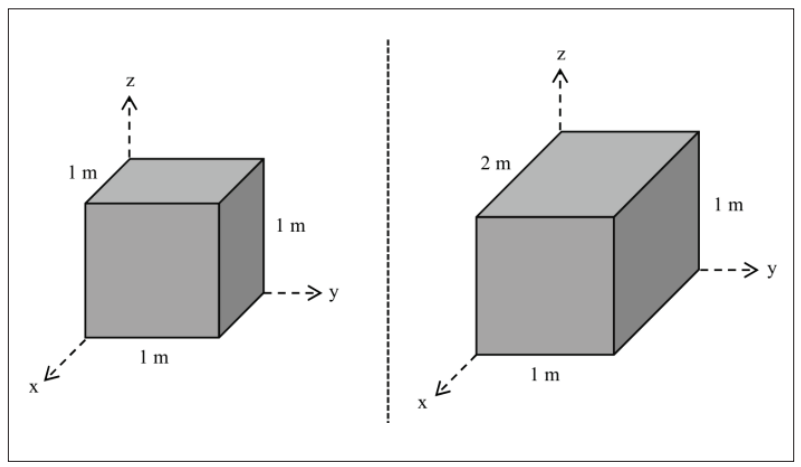

Figure 3: Concrete block dimensions

concrete systems. Generally, the pipe systems do not have regular/symmetric layouts, so, application of $2 \mathrm{D}$ modelling for such a scenario is problematic. It is noted that the finite element (FE) simulation potential for the pipe-cooled concrete systems has been extensively explored (Myers et al., 2009; Liu et al., 2015; Zhong et al.,

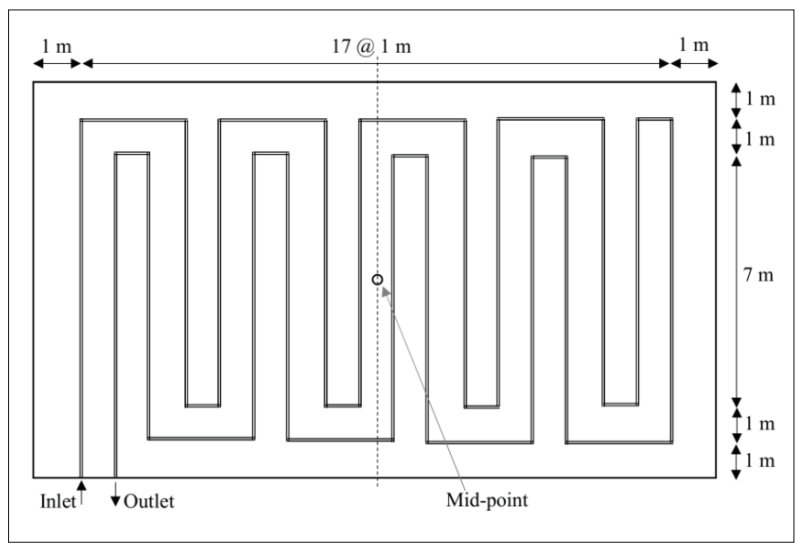

Figure 4: Pipe network arrangement (Kim et al., 2001)

2017). In order to observe the possibility of extending the current 3D FD algorithm towards such systems, a brief attempt was made to model the temperature behaviour of the pipe-cooled concrete unit found in Kim et al. (2001). In that investigation, $11 \mathrm{~m} \times 22 \mathrm{~m} \times 2 \mathrm{~m}$ concrete footing, which comprised a pipe cooling system at the mid-plane, was cast on a $6 \mathrm{~m}$ high rock foundation. Figure 4 shows the pipe network at the mid-plane (at $1 \mathrm{~m}$ height) of the footing. The key parameters of the experiment are tabulated in Table 4.

The 3D FD algorithm was extended to incorporate the pipe-cooling system along with the suggestions found in Kim et al. (2001). Basically, the nodes in the FD formulation that are along the pipeline represented both concrete and the water pipe where the amount of heat that transfers from the concrete to the water at node $(\mathrm{m}, \mathrm{n})$ was formulated as, 
Table 4: Experimental properties

\begin{tabular}{lc}
\hline Initial concrete temperature $\left({ }^{\circ} \mathrm{C}\right)$ & 31 \\
Adiabatic temperature profile & $47\left[1-e^{-1.3(t-0.1)}\right]$ \\
Concrete thermal conductivity $\left(\mathrm{W} / \mathrm{m}^{\circ} \mathrm{C}\right)$ & 2.21 \\
Coefficient of convection to atmosphere $\left(\mathrm{W} / \mathrm{m}^{2}{ }^{\circ} \mathrm{C}\right)$ & 10.5 \\
Water volume $\left(\mathrm{m}^{3} / \mathrm{h}\right)$ & 1.08 \\
Water velocity $(\mathrm{m} / \mathrm{s})$ & 0.6 \\
Inlet temperature $\left({ }^{\circ} \mathrm{C}\right)$ & 25 \\
Thermal conductivity of water $\left(\mathrm{W} / \mathrm{m}^{\circ} \mathrm{C}\right)$ & 0.644 \\
Specific heat of water $\left(\mathrm{kJ} / \mathrm{kg}{ }^{\circ} \mathrm{C}\right)$ & 4.2 \\
Pipe diameter $(\mathrm{mm})$ & 25.4 \\
\hline
\end{tabular}

$$
h_{w} \pi D\left(T_{c_{m, n}}-T_{w_{m, n}}\right) \frac{1}{V}
$$

where, $h_{w}$ is the heat transfer coefficient of water, $D$ is the pipe diameter, $T_{c_{m, n}}$ is the concrete temperature at node $(m, n), T_{w_{m, n}}$ is the water temperature at node $(m, n)$, and $V$ is the volume of concrete. The governing differential equation for a node that represents both concrete and water then becomes,

$$
\begin{gathered}
k\left(\frac{\partial^{2} T}{\partial x^{2}}+\frac{\partial^{2} T}{\partial y^{2}}+\frac{\partial^{2} T}{\partial z^{2}}\right)+\frac{\partial q}{\partial t}=\rho C_{P} \frac{\partial T}{\partial t}+ \\
h_{w}(\pi D d)\left(T c_{m, n}-T w_{m, n}\right) \frac{1}{V}
\end{gathered}
$$

whilst the other concrete nodes are represented from equation (3).

The heat transfer coefficient of water was approximated by Kim et al. (2001) as,

$h_{w}=4.75 u+43$

where $u$ is the water velocity. Here, $h_{w}$ is in $\mathrm{kcal} / \mathrm{m}^{2} \mathrm{hr}$ ${ }^{\circ} \mathrm{C}$, and $u$ is in $\mathrm{cm} / \mathrm{s}$, which is valid for $20 \leq u \leq 60 \mathrm{~cm} / \mathrm{s}$. Kim et al. (2001) further showed that the temperature of node $(m, n+1)$ of water could be found from,

$T_{w_{m, n+1}}=\frac{\left(C_{1}-C_{2}\right) T_{w_{m, n}}+C_{2} T_{c_{m, n}}}{C_{1}}$

where,

$C_{1}=Q_{w} \rho_{w} C_{w}$

and,

$C_{2}=h_{w} \pi D \Delta$
Here $Q_{w}$ is the flow rate, $\rho_{w}$ is the density of water, $C_{w}$ is the specific heat capacity of water, $\Delta$ is the nodal distance.

\section{RESULTS AND DISCUSSION}

\section{Validation results}

The FD predictions and the experimental results pertaining to the temperature profile at the centre of each block were compared to verify the prediction model potential. Figures 5(a) to (c) illustrate the comparison of experimental and predicted temperature profiles for each experiment. Table 5 summarizes the comparison for the peak temperature and the corresponding time.

As highlighted in Figures 5(a)-(c), the temperature profiles were predicted with reasonable accuracy. The slight prediction discrepancy noted over the temperature descending branch of the Madupushpa et al. (2017) experiment could be possibly due to the secondary cast, which was not incorporated into the prediction model. Table 5 indicates that the maximum deviation for the peak temperature prediction was $2.2 \%$, and the maximum deviation for the time of reaching the peak temperature was $15 \%$. Since the peak temperature has more significance than the timing, this prediction accuracy can be deemed satisfactory. Interestingly, Tahershima and Tikalshy (2017) showed that the level of prediction accuracy in their FE element approach in terms of peak temperature and its time were $0.2 \%$ and $9.6 \%$, respectively. Hence, the potential of the FD approach was, in fact, fairly close to the FE potential. The FD simulations were of cause associated some approximate level of thermal parameters, and hence, there is still room for further 
improving the FD prediction accuracy. Furthermore, the incorporation of time-dependent behaviour of the key parameters (e.g. thermal conductivity) may also improve the prediction precision.

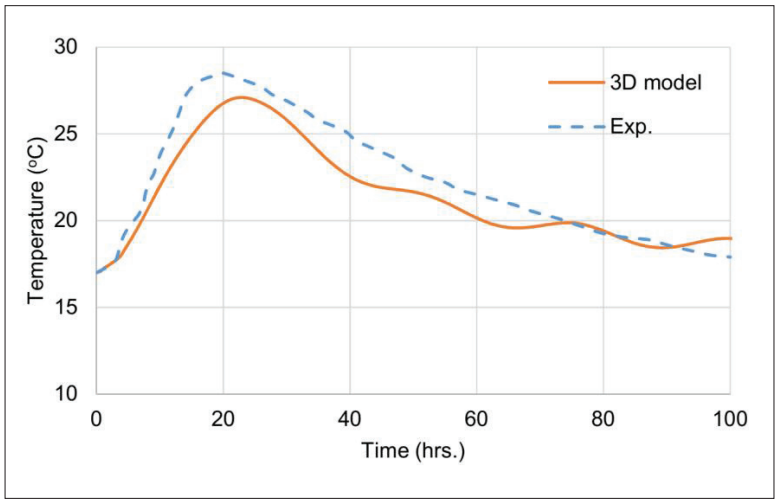

(a)

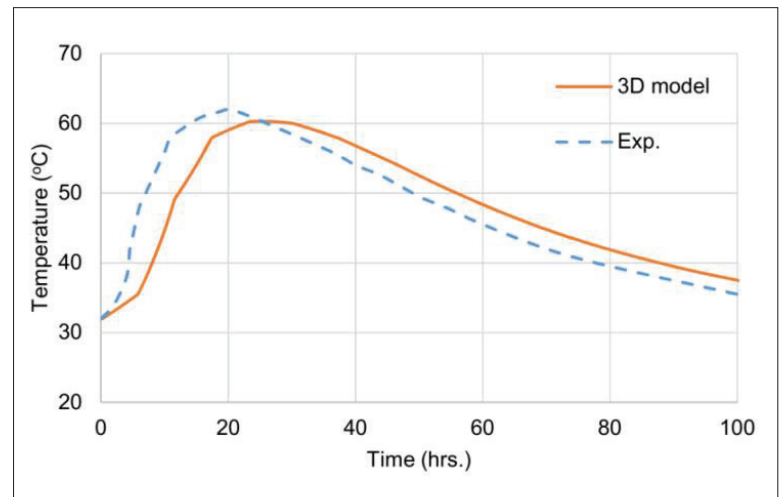

(b)

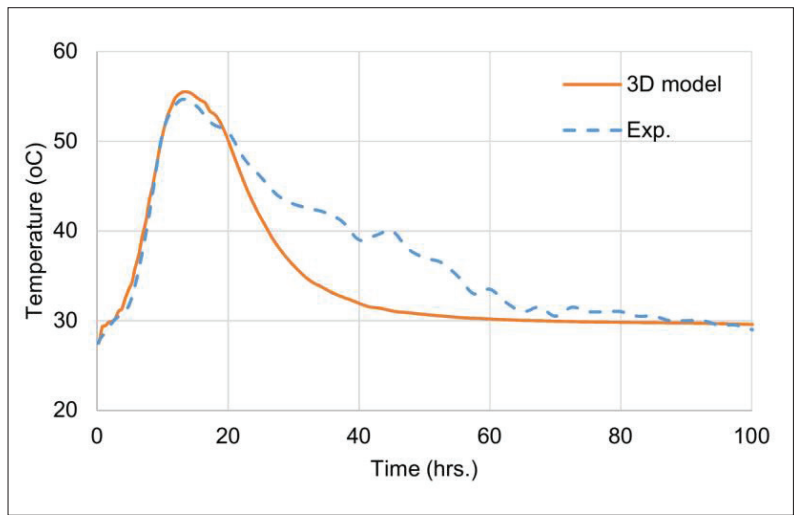

(c)

Figure 5: Center node temperature variation: (a) Ballim (2004); (b) Nanayakkara and Wannigama (2003); (c) Madupushpa et al. (2017)

Table 5: Validation results

\begin{tabular}{lcccc}
\hline \multirow{2}{*}{ Experiment } & \multicolumn{2}{c}{ Validation results } & \multicolumn{2}{c}{ FD prediction (deviation \%) } \\
\cline { 2 - 5 } & $\begin{array}{c}\text { Peak } \\
\text { temperature } \\
\left({ }^{\circ} \mathrm{C}\right)\end{array}$ & $\begin{array}{c}\text { Time } \\
\text { (hours) }\end{array}$ & $\begin{array}{c}\text { Peak } \\
\text { temperature } \\
\left({ }^{\circ} \mathrm{C}\right)\end{array}$ & $\begin{array}{c}\text { Time } \\
\text { (hours) }\end{array}$ \\
\hline Ballim (2004) & 28 & 20 & $27.1(1.9 \%)$ & $23(15 \%)$ \\
Nanayakkara \& Wannigama (2003) & 62 & 20 & $60.3(2.2 \%)$ & $25.25(11 \%)$ \\
Madupushpa et al. (2017) & 54.5 & 12.5 & $55.5(1.4 \%)$ & $13.5(8 \%)$ \\
\hline
\end{tabular}

\section{Parametric study results}

Figures 6 and 7 compare the predicted 2D and 3D temperature profiles for the central point of these two scenarios, respectively. It is noted that for the $2 \mathrm{D}$ predictions, $1 \mathrm{~m} \times 1 \mathrm{~m}$ central vertical cross section was considered to be the heat flowing cross section for each analysis. The inputs for the algorithm were: $\Delta=100 \mathrm{~mm}$, $\rho=2349 \mathrm{~kg} / \mathrm{m}^{3}, c=1.13 \mathrm{~J} / \mathrm{g}{ }^{\circ} \mathrm{C}, \quad k=2.5 \mathrm{~W} / \mathrm{m}^{\circ} \mathrm{C}$, $k_{R}=1.2 \mathrm{~W} / \mathrm{m}{ }^{\circ} \mathrm{C}, T_{R}=29{ }^{\circ} \mathrm{C}, h_{\text {plywood }}=6.5 \mathrm{~W} / \mathrm{m}^{2}{ }^{\circ} \mathrm{C}$, 
$h_{\text {air }}=23 \mathrm{~W} / \mathrm{m}^{2}{ }^{\circ} \mathrm{C}, t_{s}=18$ hours, $T_{a}=29{ }^{\circ} \mathrm{C}$ and $T_{0}=30^{\circ} \mathrm{C}$. The adiabatic temperature profile found in the Madupushpa et al. (2017) investigation was used to represent concrete with a cement content of about $500 \mathrm{~kg} / \mathrm{m}^{3}$.

As shown in Figure 6, for the length/ width ratio of one $(l / w=1)$, a difference of about $1{ }^{\circ} \mathrm{C}$ between the $2 \mathrm{D}$ and $3 \mathrm{D}$ predictions for the maximum temperatures was observed. Also, a significant prediction discrepancy was observed along the descending branch. In contrast, Figure 7 shows that the two predictions were almost similar for the cuboid $(l / w=2)$ application. As expected, when $l / w=1$, the heat flow in all three directions is significant in contrast to the $l / w=2$ condition, where the heat flow along the length $(x)$ is less significant. It is therefore, reasonable to expect the $2 \mathrm{D}$ model to make over predictions for the $l / w=1$ case. Despite the discrepancy for the maximum temperature prediction is not found large, considerable prediction disparity along the descending branch of the 2D model could be

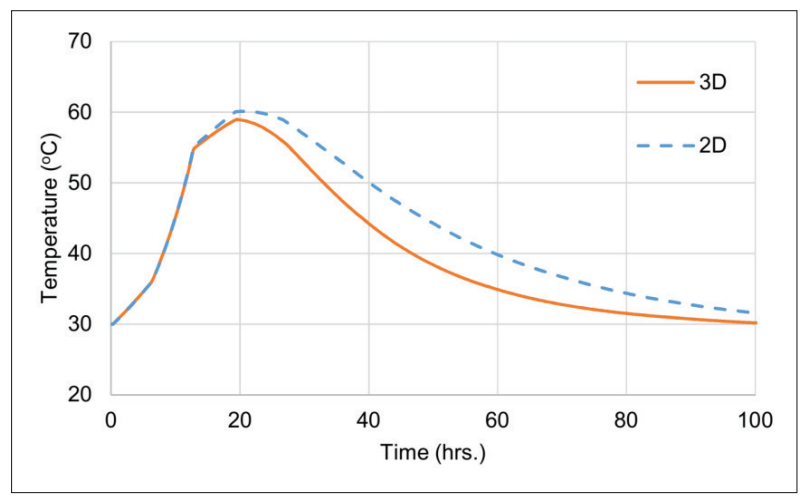

Figure 6: Temperature profiles for the cube $(l / w=1)$ unit

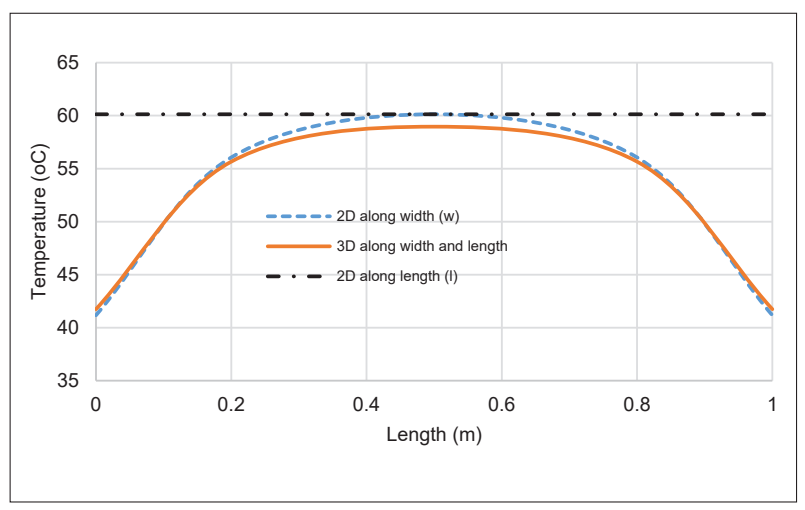

Figure 8: Temperature profiles at the peak temperature (at $20 \mathrm{hrs)} \mathrm{of}$ the cube $(l / w=1)$ unit a concern in terms of assessing temperature differentials across the mass, and this fact will be elaborated in the following section.

As a further extension of the parametric study, the 2D and $3 \mathrm{D}$ temperature predictions at 20 hours (when peak temperature occurs) along the central width (parallel to $y$-axis in Figure 3) and the central length (parallel to $x$-axis in Figure 3 ) of each concrete block were compared. Figure 8 shows those predictions for the $l / w=1$ block. It is found that, as previously observed, $1{ }^{\circ} \mathrm{C}$ prediction discrepancy at the middle of the block diminishes towards the block edges along the width of the block. Despite the 2D model assuming the temperature along the length to be uniform, the 3D prediction shown in Figure 8 depicts that it actually varies significantly towards the edges.

Figures 9 and 10 compare 2D and 3D temperature predictions along the width and length for the cuboid $(l / w=2)$ case, respectively. As previously highlighted, it is shown in Figure 9 that both types of predictions along the width were almost similar. Yet again, along the length

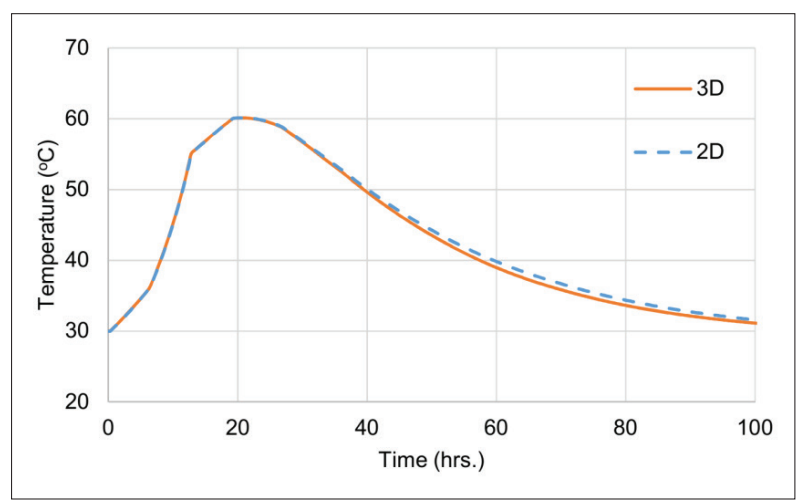

Figure 7: Temperature profiles for the cuboid $(l / w=2)$ unit

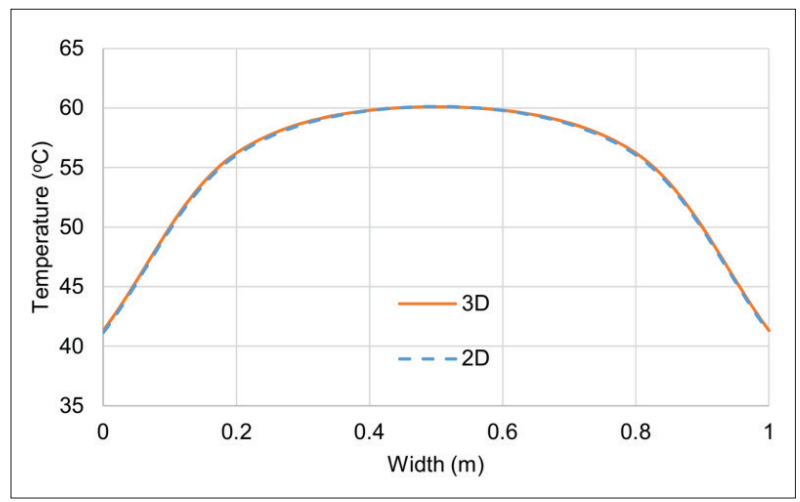

Figure 9: Temperature profiles along the width at peak temperature of the cuboid $(l / w=2)$ unit 
(x-direction), the 2D approach assumes it to be constant, whereas the 3D profile follows the actual behaviour, see Figure 10. It is however of note that, along the length, the temperature persists to be stable for a longer length in the $l / w=2$ block than in the $l / w=1$ block.

Figure 11 depicts a comparison of 2D and 3D temperature predictions along the width of the $l / w=1$ block at 50 hours (in the post-peak region). In contrast to the behaviour illustrated in Figure 8 , it is noted that the discrepancy between the two types of predictions in the post-peak behaviour is much considerable. As observed in adiabatic vs. semi-adiabatic temperature behaviours for concrete ( $\mathrm{Ng}$ et al., 2008), during the ascending branch, heat generation dominates, whereas in the descending branch, heat dissipation dominates. Since the heat generation is mostly uniform across the concrete mass whereas the heat dissipation is vastly governed by

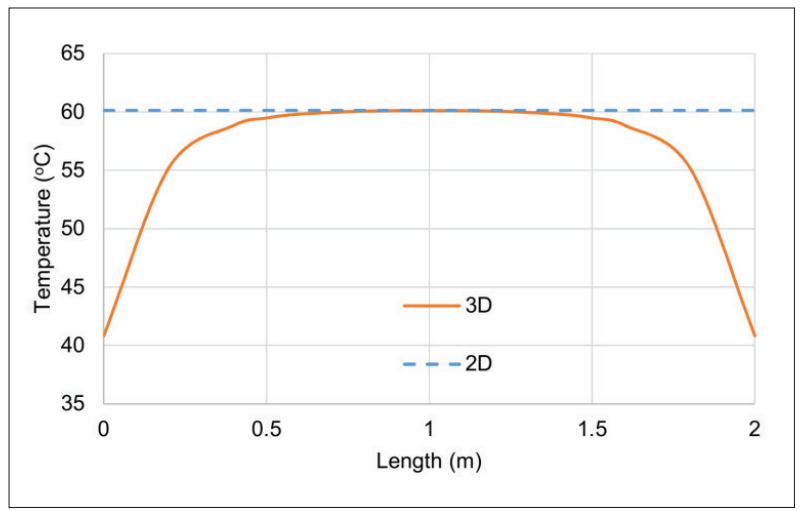

Figure 10: Temperature profiles along length at peak temperature for the cuboid $(l / w=2)$ unit

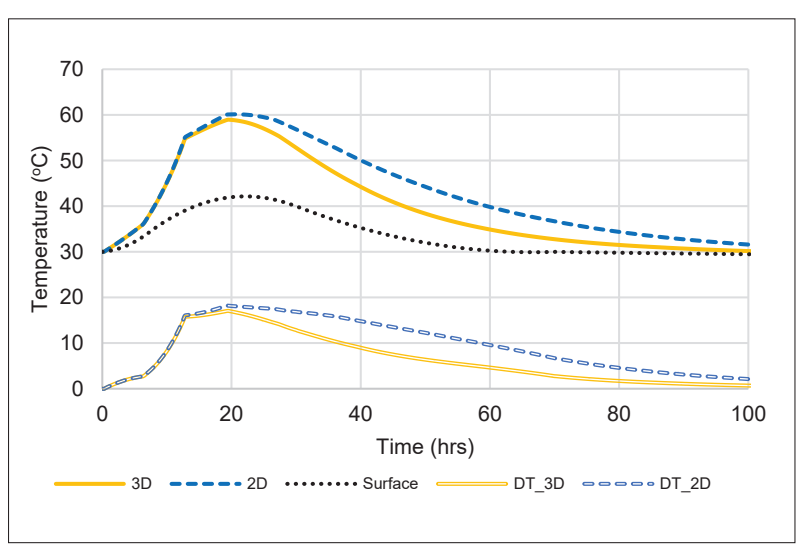

Figure 12: Temperature rise and differential for the cube $(l / w=1)$ unit the location, in view of concrete temperature modelling, simulation of heat dissipation could be the challenge. For these reasons, it is fair to expect a larger prediction disparity in the post-peak temperature region between the $2 \mathrm{D}$ and $3 \mathrm{D}$ prediction models. In view of assessing the temperature differential across the mass (to check thermal cracking issues), such prediction inaccuracies in the $2 \mathrm{D}$ model could result in over-conservative warnings. Figure 12 depicts the computed temperature difference for each type of simulation, where it clearly highlights the overprediction level of the 2D FE based temperature differential during the post-peak region.

Thus, the parametric analysis highlights the significance of applying a 3D approach for FD based temperature modelling for concrete structures when the structure is of cube shape and when the temperature gradients are to be assessed accurately.

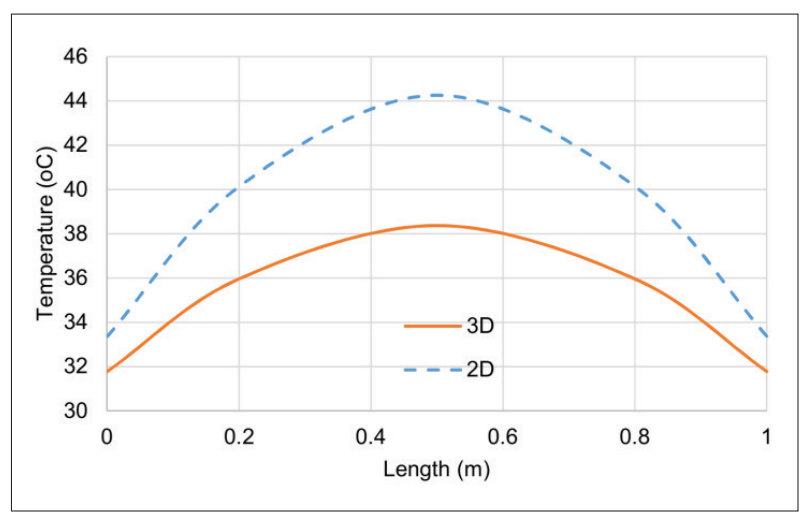

Figure 11: Temperature profiles along length after 50 hours for the cube $(l / w=1)$ unit

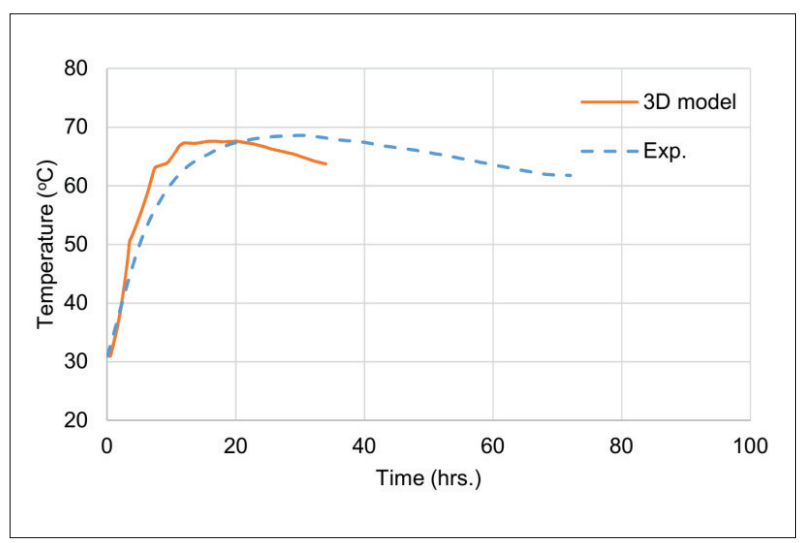

Figure 13: Centre node temperature variation 


\section{Pipe-cooled concrete simulation results}

Figure 13 compares the 3D FD modelling results with the experimental prediction of Kim et al. (2001) for the centre node of the concrete block. As depicted, the experimental maximum temperature at the centre node was about $68.6^{\circ} \mathrm{C}$, whereas the predicted maximum was about $67.6{ }^{\circ} \mathrm{C}$; hence the deviation was below $1.4 \%$. However, there is a considerable discrepancy between the experimental and predicted result in terms of the time to reach a maximum temperature where the deviation was about $33.3 \%$. It has to be noted that during the validation step in the current study, the predicted time was ahead of the actual. However, in this case, it is vice-versa. Hence, the rate of heat absorption by the water has not accurately been captured by the current FD version, and therefore, further tuning up of the model is necessary. Such improvement of the 3D FD model is identified as a matter for future work.

\section{CONCLUSIONS}

An existing 2D Finite Difference (FD) model was extended into the 3D form in order to expand its capacity to predict the early age temperature profile of concrete. The potential of the developed 3D tool was verified for three distinct experiments found in the literature. The prediction accuracy was impressive, and the maximum deviation for the peak temperature and the pertaining time predictions were less than $2.2 \%$ and $15 \%$, respectively. In addition, a parametric study highlighted the significance of using 3D temperature modelling in contrast to using 2D modelling for cube shape structures where the heat flow in all three $(x, y, z)$ directions is significant. The applicability of the 3D approach to model concrete masses that comprise internal pipe cooling networks was also investigated and need further improvements.

\section{Conflicts of interest}

The authors declare that there is no conflict of interest.

\section{REFERENCES}

Azenha M., Lameiras R., Sousa C. \& Barros J. (2014). Application of air cooled pipes for reduction of early age cracking risk in a massive RC wall. Engineering Structures 62-63(15): 148-163.

DOI: https://doi.org/10.1016/j.engstruct.2014.01.018

Ballim Y. (2004). A numerical model and associated calorimeter for predicting temperature profiles in mass concrete. Cement and Concrete Composites 26: 695-703.

DOI: https://doi.org/10.1016/S0958-9465(03)00093-3
Ballim Y. \& Graham P.C. (2003). A maturity approach to the rate of heat evolution in concrete. Magazine of Concrete Research 55(3): 249-256.

DOI: https://doi.org/10.1680/macr.55.3.249.37571

Bamforth P.B. (2007). Early-Age Thermal Crack Control in Concrete. CIRIA, London, UK.

Bobko C.P., Zadeh V.Z. \& Seracino R. (2015). Improved Schmidt method for predicting temperature development in mass concrete. ACI Materials Journal 112(4): 579-586. DOI: https://doi.org/10.14359/51687454

Dissanayake D.M.M.P., Dissanayake D.M.M. \& Yapa H.D. (2017). Numerical modelling of temperature development in concrete comprising pipe-cooling networks. Proceedings of the $8^{\text {th }}$ International Conference on Structural Engineering and Construction Management, Kandy, Sri Lanka, pp. 18-27.

Holman J.P. (1986). Heat Transfer. International Student Edition. McGraw-Hill Book Company, Singapore.

Kim J.K., Kim K.H. \& Yang J.K. (2001). Thermal analysis of hydration heat in concrete structures with pipe-cooling system. Computers and Structures 79: 163-171. DOI: https://doi.org/10.1016/S0045-7949(00)00128-0

Liu X., Zhang C., Chang X., Zhou W., Cheng Y. \& Duan Y. (2015). Precise simulation analysis of the thermal field in mass concrete with a pipe water cooling system. Applied Thermal Engineering 78(5): 449-459.

DOI: https://doi.org/10.1016/j.applthermaleng.2014.12.050

Madupushpa K.D., Kahatapitiya N.K.S.S. \& Yapa H.D. (2017). Numerical prediction of concrete temperature. Proceedings of the $5^{\text {th }}$ International Symposium on Advances in Civil and Environmental Engineering Practices for Sustainable Development, Sri Lanka, pp. 347-354.

Mataraarachchi A.I.G.K., Nanayakkara S.M.A. \& Asamoto S. (2012). Control of thermal cracking in concrete water retaining structures, Proceedings of the Second Annual Sessions, Society of Structural Engineers Sri Lanka, Colombo.

Myers T.G., Fowkes N.D. \& Ballim Y. (2009). Modeling the cooling of concrete by piped water. Journal of Engineering Mechanics 135(12): 1375-1383.

DOI:https://doi.org/10.1061/(ASCE)EM.1943-7889.0000 046

Nanayakkara S.M.A. \& Wannigama W.R.K. (2003). Experimental investigations on temperature rise due to heat of hydration. Annual transaction of Institution of Engineers, Sri Lanka, pp. 9-15.

Neville A.M. (2011). Properties of Concrete, $5^{\text {th }}$ Edition. Pearson Education Ltd., Harlow, UK.

Ng P.L., Ng I.Y. \& Kwan A.K. (2008). Heat loss compensation in semi-adiabatic curing test of concrete. ACI Materials Journal 105(1): 52-61.

DOI: https://doi.org/10.14359/19207

Patini A. (2011). Numerical analysis of temperature development in concrete at an early age. MSc thesis. University of Witwatersrand, Johannesburg, South Africa.

Riding K.A., Poole J.L., Schindler A.K., Juenger M.C. \& Folliard K.J. (2006). Evaluation of temperature prediction methods for mass concrete members. ACI Materials 
Journal 103(5): 357-365.

DOI: https://doi.org/10.14359/18158

Soutsos M., Hatzitheodorou A., Kwasny J. \& Kanavaris F. (2017). Effect of temperature on the strength development of mortar mixes with GGBS and fly Ash. Magazine of Concrete Research 69(15): 787-801.

DOI: https://doi.org/10.1680/jmacr.16.00268

Tahersima M \& Tikalsky P. (2017). Finite element modeling of hydration heat in a concrete slab-on-grade floor with limestone blended cement. Construction and Building Materials 154: 44-50.

DOI: https://doi.org/10.1016/j.conbuildmat.2017.07.176

Taylor H.F.W., Famy C. \& Scrivener K.L. (2001). Delayed ettringite formation. Cement and Concrete Research 31(5): 683-693.

DOI: https://doi.org/10.1016/S0008-8846(01)00466-5

Wasala W.M.T.D. \& Yapa H.D. (2017). Prediction of temperature development in concrete using semi-adiabatic temperature measurements. Engineer: Journal of the Institution of Engineers, Sri Lanka 50(3): 1-8.

DOI: https://doi.org/10.4038/engineer.v50i3.7261

Yang J., Hu Y., Zuo Z., Jin F. \& Li Q. (2012). Thermal analysis of mass concrete embedded with double-layer staggered heterogeneous cooling water pipes. Applied Thermal Engineering 35: 145- 156.

DOI: https://doi.org/10.1016/j.applthermaleng.2011.10.016

Yikici T.A. \& Chen H. (2015). Numerical prediction model for temperature development in mass concrete structures. Journal of the Transportation Research Board 2508(1): 102-110.

DOI: https://doi.org/10.3141/2508-13

Zhong R., Hou G. \& Qiang S. (2017). An improved composite element method for the simulation of temperature field in massive concrete with embedded cooling pipe. Applied Thermal Engineering 124: 1409- 1417.

DOI: https://doi.org/10.1016/j.applthermaleng.2017.06.124 